\title{
THE ERADICATION OF THE INVASIVE RED PALM WEEVIL IN THE CANARY ISLANDS
}

\author{
M. FAJARDO ${ }^{1}$, X. RODRÍGUEZ ${ }^{2}$, C. D. HERNÁNDEZ ${ }^{2}$, \\ L. BARROSO ${ }^{2}$, M. MORALES ${ }^{2}$, A. GONZÁLEZ ${ }^{3}$ AND R. MARTÍN ${ }^{3}$ \\ ${ }^{1}$ IPM Independent Consultant, Project Manager; fajardo_innfforma@yahoo.es \\ ${ }^{2}$ Gestion del Medio Rural de Canarias, Santa Cruz de Tenerife, Spain \\ ${ }^{3}$ Gobierno de Canarias, Santa Cruz de Tenerife, Spain
}

\begin{abstract}
SUMMARY
After the first detection in 2005 of the Red Palm Weevil (RPW), Rhynchophorus ferrugineus, in the Canary Islands, the Government of the archipelago established and implemented the RPW regional eradication programme. The area-wide application of different control measures in a coordinated and integrated way for 10 years has resulted in the eradication of this invasive pest in the archipelago. The last pest focus, located on the Island of Fuerteventura, was declared eradicated in May 2016. In this paper, the different control measures that were applied, as well as the way they were executed, are discussed. Special attention is given to the factors considered key to success. It is concluded that, with the knowledge and techniques available, the eradication of RPW is possible under favourable political and financial circumstances. The biggest threats to the success of this programme originated in human factors, rather than in intrinsic characters of the insect or the techniques used.
\end{abstract}

Key Words: Rhynchophorus ferrugineus, Phoenix spp., date palms, eradication programme, Gran Canaria, Fuerteventura, Tenerife, geographic information system, Spain

\section{INTRODUCTION}

The Canary Islands date palm, Phoenix canariensis hort. ex Chabaud is endemic to the Canary Islands, where it can be found naturally in valleys and ravines and as an ornamental tree in public and private gardens and parks. It is one of the most emblematic elements of biodiversity in the Canary Islands landscape.

In the first decade of the $21^{\text {st }}$ century, real estate boomed in the Canary Islands and this led to a drastic increase in the import of adult palm trees, especially the date palm, Phoenix dactylifera L. This is how the red palm weevil (Rhynchophorus ferrugineus Olivier) (RPW) entered the Canary Islands, posing a serious threat to the conservation of $P$. canariensis. 
The RPW was first detected on the Island of Fuerteventura in September 2005 (Martín et al. 2013). This introduction most likely originated from the import of date palms from Egypt for ornamental purposes. Subsequently, inspections begun in the areas where $P$. dactylifera imports had taken place in the previous 6 years. In this way 11 new infested areas were found, 7 in Gran Canaria and 4 in Fuerteventura. Inside these 11 areas different phytosanitary measures were implemented, including surveillance (palm tree inspection and maintenance of a RPW trapping network) and removal and destruction of infested palm trees. However, the programme as outlined below was more than a sum of these activities.

The RPW regional eradication programme was initiated in September 2006. It was implemented by the Canary Islands Government public company 'Gestión del Medio Rural de Canarias', and co-funded by the Spanish Ministry of Agriculture.

\section{THE PROGRAMME}

\subsection{Centralised Coordination and Organigramme}

Especially in projects that involve separate and different geographic areas (e.g. different islands), each one with their responsible administration, there is always a tendency of projects to be implemented in a different way according to local ideas. Therefore, a centralised coordination unit, as well as a programme structure that was transparent, proved to be vital to reach the objectives of the project.

The organogram of the programme is shown in Fig. 1. The entire team consisted up to 35 people and each team on each of the three affected islands with RPW infestations (Gran Canaria, Fuerteventura and Tenerife, where the only RPW focus was detected in 2007) was headed by an island team leader. Efficient programme management proved to be the most difficult challenge and that was already obvious during the initial phases of the implementation of the project. Different aspects of project management and implementation resulted more challenging than the technical-scientific knowledge of the pest. These included establishing an efficient team, keeping track of the project objectives, efficient communication, effective coordination between institutions, and strict adherence to established protocols.

\subsection{Legislative Measures}

Since the detection of the RPW in Europe, all Governments, including the Canary Islands Government and the Island Councils, made legislative efforts, within the scope of their responsibilities, to arm themselves with legal instruments to control RPW. During de development of the eradication programme, the basic framework for the adopted measures was derived from:

APA/94/2006, 26 January, amending the Order of 12 March 1987 to prohibit the importation of plants of palm species (Palmae) of more than $5 \mathrm{~cm}$ of base diameter into the Autonomous Community of the Canary Islands (BOE No. 24 of 1/28/2006) (APA 2006).

Commission Decision 2007/365/EC of 25 May 2007 adopting emergency measures to prevent the introduction into and the spread within the European 
Community of Rhynchophorus ferrugineus (Olivier) and its subsequent amendments. (OJ L139 / 24 of 31/05/2007) (OJ L266 / 14 of 07/10/2008) (17/08/2010 DOCE L) (European Commission 2007).

Decree of 29 October 2007 declaring the existence of pests produced by the harmful agents Rhynchophorus ferrugineus (Olivier) and Diocalandra frumenti (Fabricius) and establishing the phytosanitary measures for their control and eradication (Boletín Oficial de Canarias no. 222, dated 6.11.2007) from the Council of Agriculture, Livestock, Fisheries and Food of the Canary Government (BOC 2007).

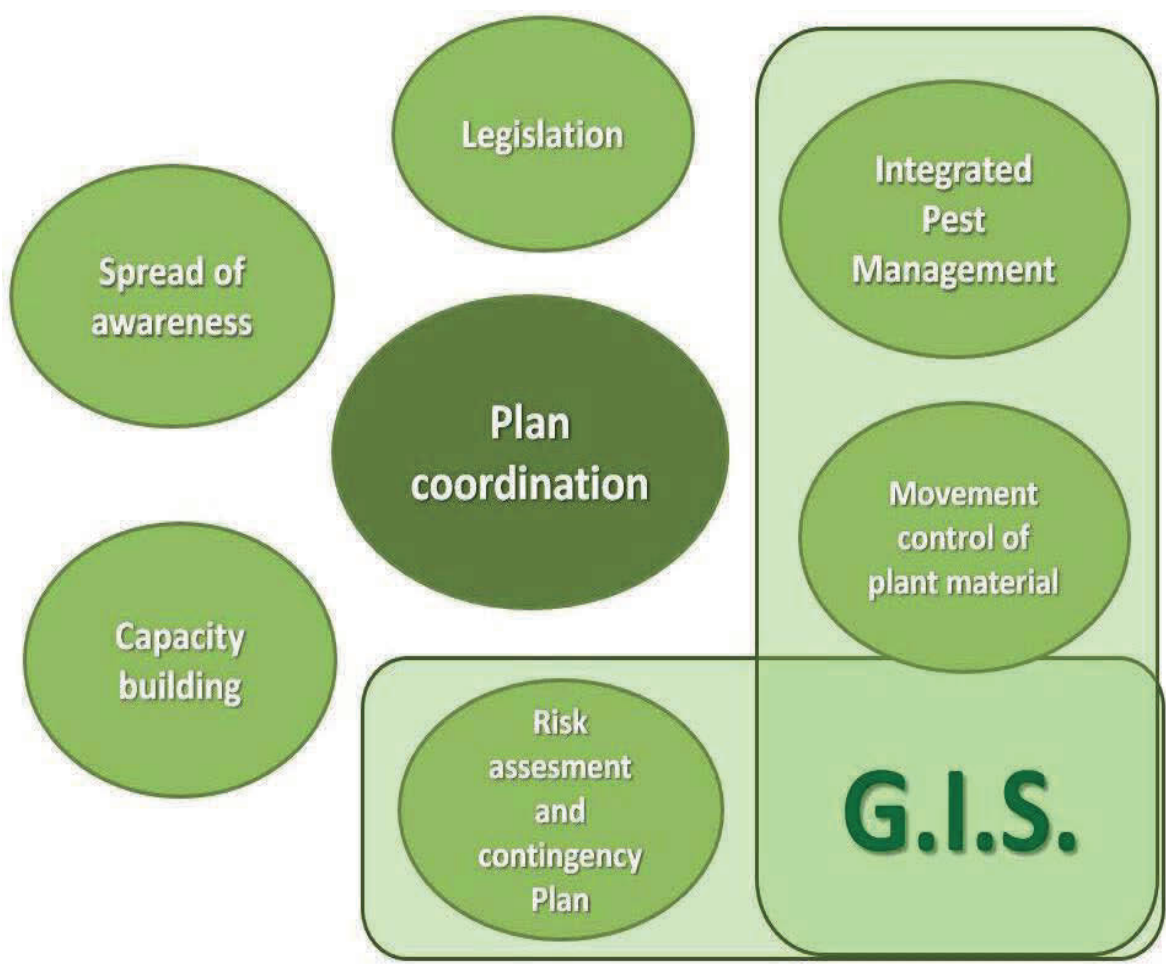

Figure 1. Red Palm Weevil Programme's organigramme.

The measures included in the regulations, at all levels, can be divided into two major groups (Gobierno de Canarias 2019a):

1. Measures that aimed at reducing man-assisted insect dispersal, including the prohibition of import of plants for planting, quarantine measures and regulations for the movement of plant material, and imposing related obligatory measures for nurseries and farmers, and

2. Measures that aimed at reducing the establishment of the pest and its natural spread after detection in a certain area. 
The measures of the first group include the control of movement of plants for planting, promotion of stakeholder awareness, and stimulation of increased cooperation between institutions. Although these measures were the most difficult to enforce, they were crucial for the success of the programme. To ensure compliance with these regulatory measures, it was necessary to include staff with legal experience on phytosanitary regulations in the multidisciplinary teams of the eradication programme.

The global economic crisis resulting from the great recession of 2008, which affected Spain particularly hard, proved indirectly to be a bonus that made the implementation of the RPW quarantine and eradication measures easier. In the precrisis period, the Spanish economy was increasingly biased towards the construction sector because of a credit and real estate bubble (Jimeno and Santos 2014). The bursting of this bubble drastically reduced the number of requested permits for the construction of new real estate in Spain from close to a million per year before the crisis to less than 200000 per year following the crisis. As a result, the demand for importing, transplanting and moving of palms from nurseries to new real estate sites was significantly reduced (Fig. 2).

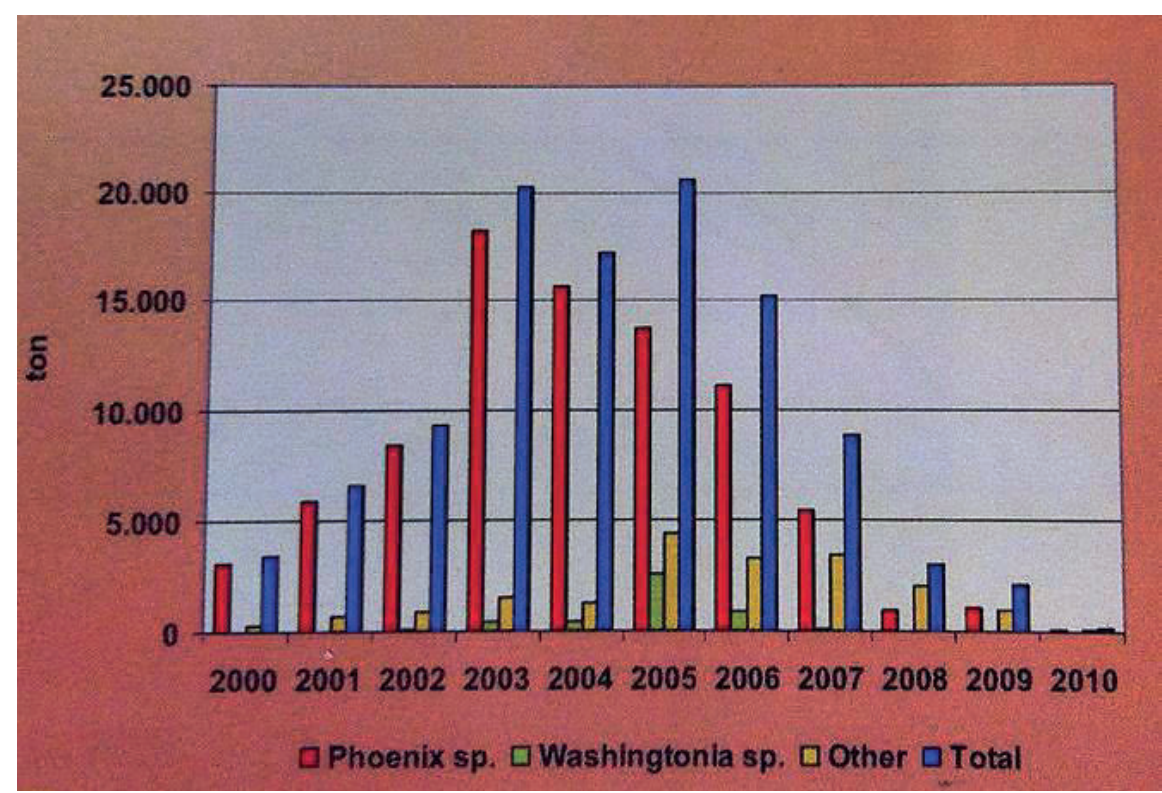

Figure 2. Tons of imported palm trees into Spain (source: Jose Maria Cobos, Spanish Ministry of Agriculture). 


\subsection{Awareness Campaigns}

To involve as many people as possible in the eradication campaign, several information and awareness campaigns accompanied the programme to provide training and information to all stakeholders and citizens. These stakeholders included engineers, technicians and staff of the different public administrations, as well as gardeners in hotels, gardening companies, plant nurseries and the general public. The main goal was to achieve optimal support from the public in reporting and alerting the programme management board immediately when observing a palm tree with suspicious symptoms. This reporting system of the general public was crucial to implement quick follow-up actions. The following communication tools were used:

- A specific web page (Gobierno de Canarias 2019b)

- TV advertising campaigns

- Information on DVDs

- Conferences and special workshops held on each one of the islands

- Brochures.

One of the crucial factors in this communication campaign was complete transparency, and to openly disclose all available information. In this way, all stakeholders became "co-owners" of the programme and felt confident and involved.

\subsection{Specific Training}

The Order of October 2007 stipulated that anybody working on palm trees should be accredited as "Specialist on labour on palm trees". The objective of this accreditation was to ensure that any person or company carrying out any type of work on palm trees was conversant with all methods and protocols described in the legislation and had received the necessary training to ensure proper palm tree management. To achieve this goal, several courses were organized to train-the-trainers, who obtained thereafter the necessary accreditation. The programme encouraged all official administrations and relevant academic institutions to include courses on palm tree management in their curricula. The RPW programme edited and produced the "Manual of good practices in palm trees", which was used as textbook in these courses.

\subsection{Movement of Plant Material}

Import or movement of infested plants for planting is the main route of introduction and spread of the pest over long distances. Therefore, the programme deemed it crucial to restrict and control the movement of plants. In addition, to manage the movement of palm trees from nurseries, the programme required all nurseries to be registered. Nurseries were inspected periodically with emphasis on:

- The registration of the entry and exit of palm trees

- Visual inspections of possible RPW damage and symptoms

- Application of the mandatory chemical treatments. 
A "Phytosanitary Accreditation" was created, consisting of a 6-month valid movement authorization for palms susceptible to RPW, except $P$. canariensis, $P$. dactylifera and Washingtonia spp., for which authorizations were requested for every single movement. It was mandatory to have an authorization of the Canary Islands Plant Protection Organization to perform transplantations of Phoenix spp. and Washingtonia spp. These could only be carried out by accredited companies. All requests for transplantation of palm trees located within a range of $5 \mathrm{~km}$ from infested plants were denied.

\subsection{Integrated Pest Management Programme}

The following activities were included in the integrated pest management programme: visual inspection of trees, chemical treatments, destruction of RPW-infested palms, monitoring/mass-trapping of RPW, and cultural measures such as pruning, which was only authorized for public safety reasons and should include the application of an oil painting or pruning mastic on the pruning scars. All of these are common measures implemented in control programmes world-wide (Abraham et al. 1998; Faleiro 2006; Dembilio and Jaques 2015).

\subsubsection{Delimitation}

Upon detection of a RPW infestation in a palm tree, or a group of palm trees, a new pest focus was declared, which was defined by two main areas:

Intensive surveillance area: The area with a $1 \mathrm{~km}$ radius from the outermost affected palm trees in the focus. All palm trees within this area were registered into batch, and only palms trees that were positively diagnosed with RPW were registered individually.

Guided surveillance area: The area within a $3 \mathrm{~km}$ radius from the border of the intensive surveillance area.

\subsubsection{Inspection of Palm Trees}

After testing all possible tree inspection methods available, intensive visual inspection was found to be the most effective detection method. The method consisted of a thorough observation of the stipe and all the bases of the crown's fronds. This type of inspection was performed by specialized personnel.

2.6.2.1. Inspection Inside Intensive Surveillance Area. In addition to regular inspections (about 3 inspection/palm/year) of all palm trees within the intensive surveillance area, visual inspections were carried out around each trap where RPW adults were caught, as well as around newly detected infested palm trees.

2.6.2.2. "Guided Inspections". Specialised technicians, responsible for the guided surveillance, carried out the visual inspections within the guided surveillance areas. These inspections allowed marking the location of affected palm trees outside the intensive surveillance areas that prevented the dispersal of the pest from infested areas. 
2.6.2.3. Alert System. The programme established an alert system in which any citizen could report observations of palm trees with apparent symptoms of the RPW. Through this system, five new RPW outbreaks were detected very early, which made it very easy to bring these outbreaks under control. The success of the alert system measure was facilitated by the public outreach and awareness campaigns (see above in point 2.3.).

\subsubsection{Removal of Infested Palm Trees}

All palm trees suspected of being infested with RPW were removed. In most cases, the removal took place within 24 hours after detection. In those cases where this was not possible, palms were treated and enmeshed until removal.

The removal process followed a strict disposal protocol to avoid dispersal of adult weevils during the process. The tree stump was guarded and inspected for several days after the removal and a trap was deployed next to it for at least a week.

\subsubsection{Chemical Treatments}

Chemical treatments aimed to control the immature stages of RPW found in the most superficial part of the palms. Insecticides such as chlorpyrifos $48 \%$, imidacloprid $20 \%$ and thiamethoxam $25 \%$ were sprayed on the tree at very low pressure, using about 15 litres of the mixture per palm.

Throughout the programme, chemical treatments were routinely applied (about 2 treatments/year) to all palm trees inside the intensive surveillance area, but also to palm trees around each newly detected affected palm, as well as around traps when adult specimens were caught.

\subsubsection{Trapping Networks}

Food and pheromone baited traps were deployed to maintain a trapping network following different strategies and objectives:

- Mass-trapping

- Adult weevil attraction to the centre of each pest foci

- Population monitoring

- Detection of new pest foci.

The traps were baited with $700 \mathrm{mg}$ of $R$. ferrugineus attractant (4-methyl-5 nonanol $90 \%$ and 4-methyl-5-nonanon $10 \%$, both purity $>95 \%$ ) and either ethyl acetate (kairomone) or fresh palm tissue. They were checked for weevils and serviced once a week. At an average temperature of $28^{\circ} \mathrm{C}$ the attractant is released at a rate of $11 \mathrm{mg}$ /day making the trap effective for a period of 6 to 8 weeks (product label information). The self-made four window ( $4 \mathrm{~cm}$ diameter) 10 litre bucket traps with no opening on the lid were placed at more than 15 meters from any palm tree, and if possible, were buried half in the ground. At the onset of the programme, white traps were used, but starting in 2011 these were painted black (Ávalos and Soto 2010). 
Different strategies were followed to manage the trapping networks. As recommended by Oehlschlager (1994), the programme started using a grid of 1 trap/ha in pest foci and surrounding guided surveillance areas. This was later replaced by 'dynamic micro-networks of traps', where traps were deployed at a density of 4 traps/ha in the polygons of the affected palm trees. Following this approach, no traps were deployed in areas around pest foci and their surrounding guided surveillance areas, where the presence of the pest was not proven. The objective was not to attract the weevils away from affected areas by placing traps into areas where they had not yet been observed. These networks were 'dynamic' and continuously adjusted and adapted in size based on (a) new detections of affected palms, (b) increased catches in certain areas, (c) the absence of newly infested palm trees, and (d) the absence of weevil catches. On islands with known RPW foci, traps were also placed around the areas where the infested palm trees had been disposed of.

In islands that had remained free of RPW, traps were placed in areas where imported date palm trees had been planted in the last 5 years, e.g. golf courses, hotels, newly constructed real estate projects, nurseries, etc. Using this approach, the 2007 outbreak in the Island of Tenerife was detected early.

\subsection{Contingency Planning}

As soon as a new focus was detected, a contingency plan was developed and implemented. The purpose of this contingency plan was to determine the origin of the outbreak, as well as to determine the location and to remove all infested palm trees. All human resources of the programme were dedicated to the new focus until the situation was brought under control.

\section{A TOOL: GEOGRAPHIC INFORMATION SYSTEM (GIS)}

A geographic information system (GIS) is a system designed to capture, store, manipulate, analyse, manage, and present spatial or geographic data (Foote and Lynch 1995). The eradication programme included a programming team (ITs), responsible for the development of the used GIS applications.

The GIS was the main tool supporting the decision-making process for three of the main activities of the programme (Fig. 1), i.e. the IPM programme, the control of movement of all plant material, and contingency plans.

The GIS was considered an essential tool for the planning and effective coordination of the eradication pest programme that allowed:

- Data and spatial analysis for optimal decision-making

- Efficient planning and use of resources

- Assessment of the programme (results, achievement of objectives) and workers from readily available quality information

- Improvement of the programme's internal and external communications.

The GIS consisted of four important elements: mobile applications, a database, a web application and a web viewer. 


\subsection{Database}

The main objective of the database was to store and centralise all relevant information:

- Elements of the programme, e.g. pest foci, groups of palm trees, individual palm trees, traps, nurseries

- Activities of the programme, e.g. removal of infested palm trees, inspections, chemical treatments

- Results of the programme, e.g. trap catches, inspection data etc.

- Resources of the programme, e.g. workers, type of chemical products, type of traps, pheromones.

All this information was conveniently organized and related. All other software applications developed interacted with the database, either to introduce new values (e.g. field-collected data with the mobile application) or for the processing of information (web viewer, web application) to generate reports, customized maps, etc.

\subsection{Mobile Application}

An application for mobile devices was developed to facilitate data collection in the field. It was designed to avoid mistakes when entering data resulting in great efficiency, accuracy and high data quality.

Usually, at the end of each week, each island team leader summarized the collected data using the internet. These data were stored on a web server and automatically imported into the central database of the project.

\subsection{Web Application}

A web application was developed to use the database in a more friendly and efficient way. This application allowed:

- Data entry

- Data editing

- Performing queries

- Generation of tables

- Generating graphics and reports.

\subsection{Web Viewer}

The web viewer allowed observing and analysing all the spatial information collected by the field teams. As a result, it was possible to show on a map:

- Stored data, such as lots, affected palm trees, traps, farmers and nurseries

- Customized queries, e.g. palm trees removed by date ranges, palm lots in a range of 100 meter around a trap with catches, traps categorised by the number of catches or by a date range

- New layers, e.g. areas occupied by infested palm trees and traps. 


\section{MANAGEMENT OF HUMAN RESOURCES}

The eradication programme as described above offered a framework to reach the eradication objectives. Nevertheless, for the correct implementation of all measures, it was essential to have an efficient management team. Probably the biggest challenge of any programme direction is to establish and manage this team.

The team was composed of members whose attitude towards work and internal training was considered exemplary. Efficiency in the programme was maintained as each team member was aware of the relevance of his/her role in the implementation of the programme and its ultimate success. This entailed that the objectives and procedures of each task had to be clearly defined.

To achieve the programme's objectives, great attention was given to continuous training, improved motivation of the group members and to always create and maintain a positive team spirit. At all times it was emphasised that the group members were the protagonists of the obtained results. A team member could always make suggestions and the proposals were always evaluated and sometimes incorporated into the procedures.

\section{RESULTS}

On three islands (Gran Canaria, Fuerteventura and Tenerife), sixteen RPW foci were detected and eradicated (Fig. 3). More than 70000 palm trees were registered, 706081 visual inspections were made, and 209547 chemical treatments were carried out. A total of 681 RPW adults were caught in traps (Fig. 4) and 660 palm trees removed. In May 2016, 11 years after the pest was first detected, and after three years without finding affected palm trees or catching RPW in traps, the Canary Islands were declared free of the pest.

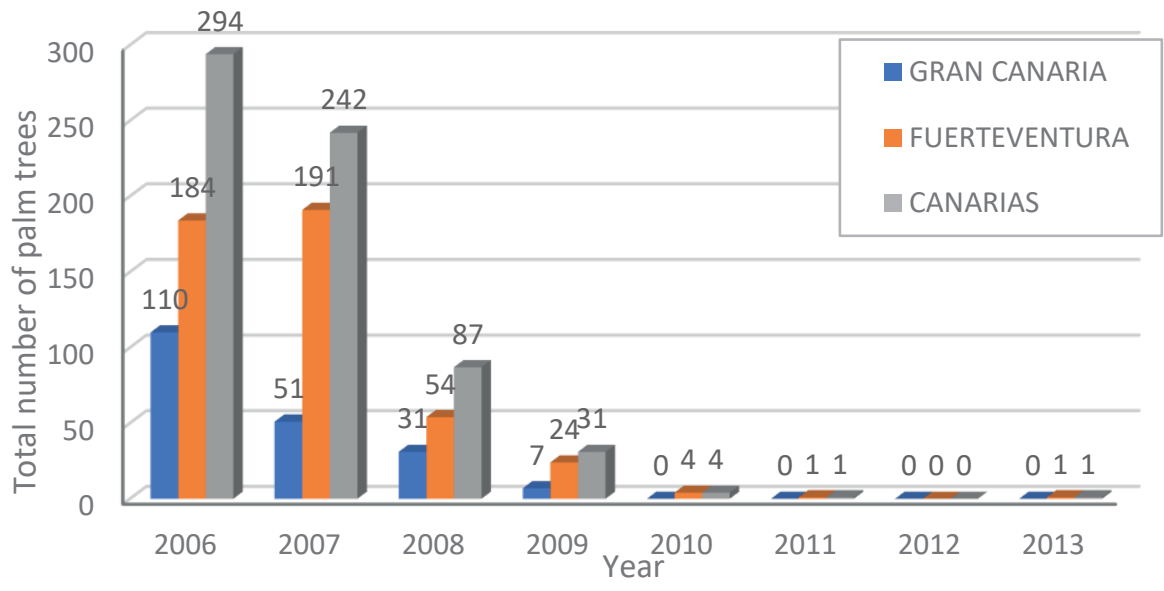

Figure 3. Affected palm trees between 2006 and 2013 on the islands of Gran Canaria and Fuerteventura, as well as total numbers for the Canaries. 


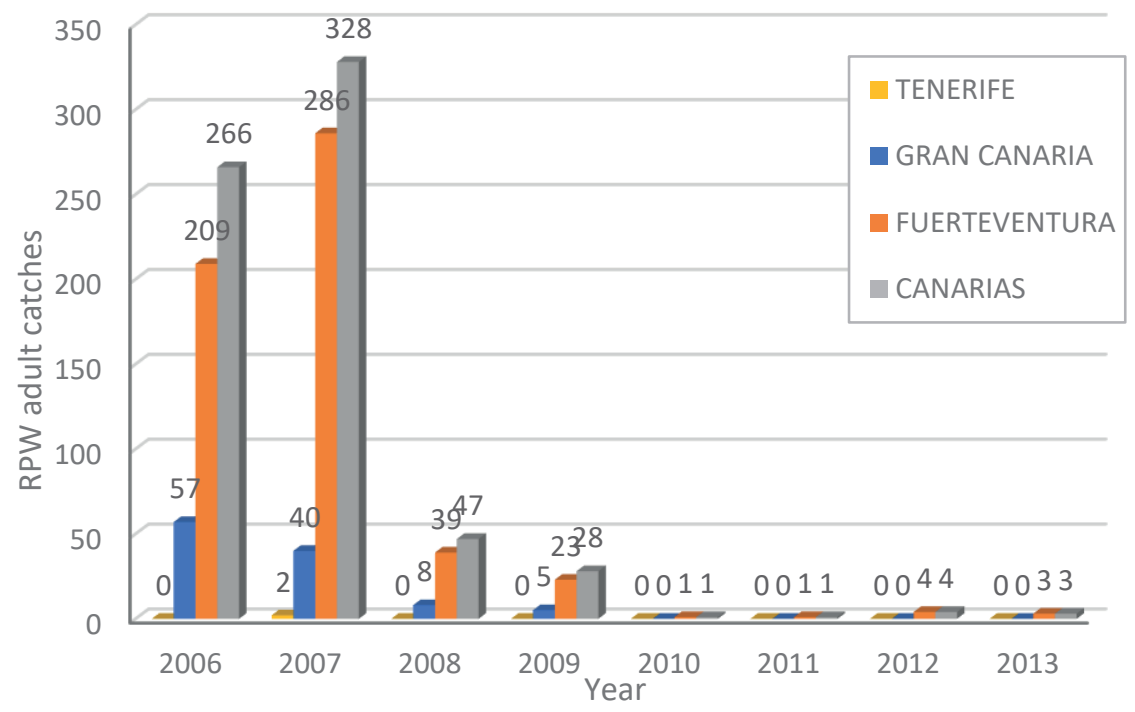

Figure 4. Red Palm Weevil adult catches in traps between 2006 and 2013 in Tenerife, Gran Canaria, and Fuerteventura, as well as total numbers for the Canaries.

The Canary Islands example shows that the presently available knowledge and control tactics can successfully eradicate the RPW. The main issue is not the lack of technical know-how, but the establishment of an efficient organization and its management to reach the objectives. The Canary Islands are now facing a new challenge and that is to maintain the motivation and support to prevent and detect early any new introduction of the RPW.

Taking into account the results and positive experience gained in the eradication programme of RPW in the Canary Islands, the minimum requirements for a successful eradication programme are as follows:

- Applying a programme in areas of recent introduction or where the RPW has been kept under control

- Identifying areas isolated from affected areas by a buffer zone with no susceptible palms or that are at least $10 \mathrm{~km}$ away from the nearest RPW focus, where no programme activities have to be applied

- Including adequate legislative measures and their enforcement aiming to avoid new introductions and the movement of plant material

- Correct design and integrated implementation of all programme's activities and components

- Adequate budget available according to the number of pest foci and other requirements

- Centralised coordination (e.g. communication, decision-making) of area-wide programme activities

- $\quad$ Adequate human resources available and their management (e.g. training, attitude, motivation, constancy procedures) 
- Effective use of GIS in support of data management and decision-making

- Public education and engagement, and involvement of all stakeholders

- Cooperation and coordination with public (Provinces, Autonomous Communities and affected Municipalities) and private entities (e.g. nurseries, gardening companies, hotels, farmers).

\section{REFERENCES}

Abraham, V. A., M. Al-Shuaibi, J. R. Faleiro, R. A. Abouzubairah, and P. S. P. V. Vidyasagar. 1998. An integrated approach for the management of red palm weevil Rhynchophorus ferrugineus Oliv. a key pest of date palm in the Middle East. Journal of Agricultural and Marine Sciences 3: 77-83.

APA (Ministerio de Agricultura, Pesca y Alimentación). 2006. Orden APA/94/2006, de 26 de enero, por la que se modifica la Orden de 12 de marzo de 1987, por la que se establecen para las islas Canarias, las normas fitosanitarias relativas a la importación, exportación y tránsito de vegetales y productos vegetales, para prohibir la importación de vegetales de especies de palmeras (Palmae) en la Comunidad Autónoma de Canarias. Documento Boletín Oficial del Estado-A-2006-1330.

Ávalos, J. A., and A. Soto. 2010. Mejora de la eficacia del trampeo de adultos de Rhynchophorus ferrugineus (Olivier) (Coleoptera: Dryophthoridae) mediante atracción cromática. Phytoma España: La Revista Profesional de Sanidad Vegetal 223: 38-42.

BOC (Boletín Oficial de Canarias) 2007. 833 - Orden 1833, de 29 de octubre de 2007, por la que se declara la existencia de las plagas producidas por los agentes nocivos Rhynchophorus ferrugineus (Olivier) y Diocalandra frumenti (Fabricius) y se establecen las medidas fitosanitarias para su erradicación y control. Boletín Oficial de Canarias número 222, martes 6 de noviembre de 2007.

Dembilio, O., and J. A. Jaques. 2015. Biology and management of red palm weevil, pp. 13-36. In W. Wakil, J. R. Faleiro, and T. A. Miller (eds.), Sustainable pest management in date palm: Current status and emerging challenges. Springer International Publishing, Switzerland.

European Commission. 2007. Commission Decision of 25 May 2007 on emergency measures to prevent the introduction into and the spread within the Community of Rhynchophorus ferrugineus (Olivier) (notified under document number C (2007) 2161) (2007/365/EC) (OJ L 139, 31.5.2007, p. 24). Amended by Commission Decision 2008/776/EC of 6 October 2008, and Commission Decision 2010/467/EU of 17 August 2010.

Faleiro, J. R. 2006. A review of the issues and management of the red palm weevil Rhynchophorus ferrugineus (Coleoptera: Rhynchophoridae) in coconut and date palm during the last one hundred years. International Journal of Tropical Insect Science 26: 135-154.

Foote, K. E., and M. Lynch. 1995. Geographic Information Systems as an Integrating Technology: Context, concepts, and definitions. Geographer's Craft Project, Department of Geography, The University of Colorado at Boulder, Colorado, USA.

Gobierno de Canarias. 2019a. El picudo rojo Rhynchophorus ferrugineus Olivier. Dossier informativo. 127 pp. Consejería de Agricultura, Ganadería, Pesca y Aguas. Consejería de Medio Ambiente y Ordenación Territorial.

Gobierno de Canarias. 2019b. Picudo rojo en Canarias. Consejería de Agricultura, Ganadería, Pesca y Aguas.

Jimeno, J. F., and T. Santos. 2014. The crisis of the Spanish economy. SERIEs 5: 125-141.

Martín, R., A. González, L. Barroso, M. Morales, C. D. Hernández, X. Rodríguez, and M. Fajardo. 2013. Plan de surveillance, de lutte et d'éradication du Charançon Rouge dans les Îles Canaries (Espagne). In Proceedings, Palm Pest Mediterranean Conference, Nice, France, 16-18 Janvier 2013, Alfortville, France. Association Française de Protection des Plantes (AFPP), France.

Oehlschlager, A. C. 1994. Use of pheromone baited traps in control of red palm weevil in the Kingdom of Saudi Arabia. Consultancy Report, Ministry of Agriculture, Riyadh, Saudi Arabia. 